\title{
A further study of acetylacetone nitrosation ${ }^{1}$
}

\section{Emilia Iglesias* and Isabel Brandariz}

Department of Química Física e E. Q. I. Facultad de Ciencias, Universidad de La Coruña, 15071-La Coruña, Spain.E-mail: emilia.iglesias@udc.es

Org. Biomol. Chem., 2013, 11, 1059-1064

Received 4th June 2012, Accepted 25th July 2012

DOI: 10.1039/C2OB26073E (Paper)

\begin{abstract}
The nitrosation of acetylacetone (AcAc) has been revised in an aqueous acid medium of perchloric acid and buffers of mono-, di-, or tri-chloroacetic acid. The results show that in the presence of buffers, under conditions of [nit] « [AcAc] (nit = sodium nitrite) the reaction cannot be studied by UV-Vis spectroscopy, contrary to the recently published paper by García-Rio et al. (J. Org. Chem., 2008, 73, 8198). The present study also corroborates the previously published mechanism of AcAc nitrosation, where no base-catalysis was observed. Contrarily, the low effect of buffers was attributed to the formation of nitrosyl chloro-, dichloro- or trichloro-acetate salts that are new nitrosating agents.
\end{abstract}

\footnotetext{
${ }^{1}$ Electronic supplementary information (ESI) available: Fig. S1 of the reaction spectrum in conditions of excess nitrite over AcAc and Tables S1-S3, listing the experimental conditions and the observed rate constants obtained in the nitrosation of $\mathrm{AcAc}$ in the presence of the buffers $\mathrm{Cl}_{3} \mathrm{Ac}, \mathrm{Cl}_{2} \mathrm{Ac}$ and $\mathrm{ClAc}$, are provided. See
} DOI: $\underline{10.1039 / \mathrm{c} 2 \mathrm{ob} 26073 \mathrm{e}}$ 


\section{Introduction}

The reaction of ketones with a variety of nitrosating agents (including nitrous acid, alkyl nitrites, nitrosyl halides, or dinitrogen trioxide) to give nitroso ketones or keto oximes - depending on the structure of the substituent adjacent to the carbonyl group - has already been discussed in a comprehensive account by Touster ${ }^{1}$ that covers the literature on the topic up to 1953.

By analogy with other reactions of ketones with electrophiles, such as halogenation, the obvious expectation is that nitrosation occurs by electrophilic addition to the enol form of the ketone. Singer and Vamplew published in 1957 the first kinetic studies of the nitrosation of acetone (Ac) - using nitrous acid - and they proposed a reaction mechanism whereby the electrophilic nitrosation occurs at the carbonyl oxygen atom followed by a rapid internal rearrangement of the NO-group to the adjacent C-atom (Scheme 1). ${ }^{2}$ The rate constant of acetone nitrosation is faster $\left(k_{\mathrm{ni}} \sim 10^{8} \mathrm{M}^{-1} \mathrm{~s}^{-1}\right)$ than the enolization rate constant $\left(k_{\mathrm{e}} \sim 10^{-5} \mathrm{M}^{-1} \mathrm{~s}^{-1}\right)$.

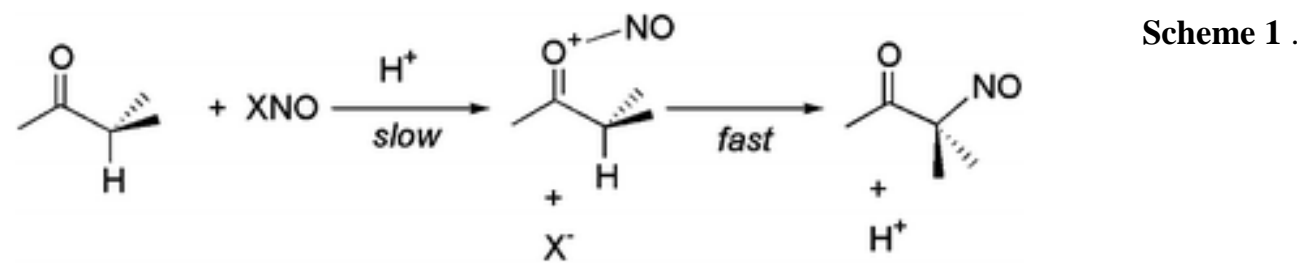

Later in 1977, the synthetic and analytic study of Rogic et al. - $^{3}$ demonstrated that the overall mechanism of the nitrosation of ketones is an electrophilic addition of the nitrosating agent to the double bond of the enol present in the equilibrium. Depending on the experimental conditions and/or on the ketone, the enolization step, $k_{\mathrm{e}}$, or the nitrosation step, $k_{\mathrm{ni}}$, can determine the reaction rate (Scheme 2).

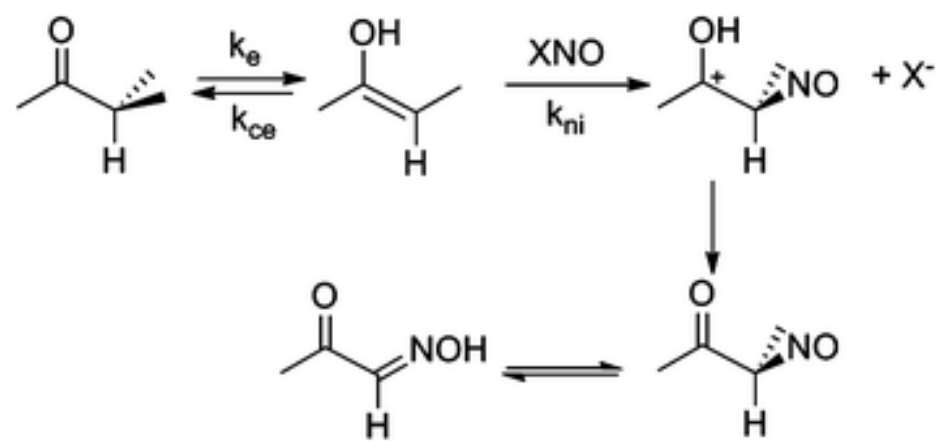

Scheme 2

In 1987, the Williams' research group carried out a detailed kinetic study of the nitrosation of ketones. $\frac{4-7}{-}$ The first study on the topic that includes the nitrosation of acetone (Ac), ethyl-methylketone (EMK), acetylacetone (AcAc), and 1,3-dichloroacetone was performed under conditions of [ketone] $\gg\left[\mathrm{HNO}_{2}\right]$, with $\left[\mathrm{HNO}_{2}\right]>2 \mathrm{mM}$ in order to be able to follow the reaction by UV-vis 
spectroscopy at $\lambda=385 \mathrm{~nm}$ where nitrous acid, the limiting reagent, absorbs. The nitrosation of simple ketones, such as Ac or EMK, in the presence of nucleophiles $\left(\mathrm{X}^{-}\right)$, e.g. $\mathrm{Br}^{-}$at $0.5 \mathrm{M}$, shows zero-order kinetics, and the zero-order rate constant increases proportionally to both ketone concentration and $\mathrm{H}^{+}$concentration, i.e., rate $=k_{\mathrm{e}}\left[\mathrm{H}^{+}\right][$ketone $]$. These kinetic observations point to a reaction mechanism where the nitrosation takes place via the enol form that is generated in the rate limiting step of the reaction; in other words, it is the enolization reaction that is being studied. In the absence of $\mathrm{Br}^{-}$, or at low halide ion concentration, the reaction rate depends on $\left[\mathrm{HNO}_{2}\right]$, i.e., the rate limiting step is now the attack of the nitrosating agent on the enol form, $k_{\mathrm{ni}}$. By contrast, the nitrosation of acetylacetone (AcAc), also under experimental conditions of $[\mathrm{AcAc}] \gg\left[\mathrm{HNO}_{2}\right]$ (with $\left[\mathrm{HNO}_{2}\right]=2.1 \mathrm{mM}$ and the ionic strength $0.5 \mathrm{M}$ controlled with $\mathrm{NaClO}_{4}$ ), is first-order in nitrous acid as well as first-order in [AcAc], $\left[\mathrm{H}^{+}\right]$and [nucleophile catalyst], with nucleophile catalyst $\mathrm{Cl}^{-}, \mathrm{Br}^{-}, \mathrm{SCN}^{-}$, or $\mathrm{SC}\left(\mathrm{NH}_{2}\right)_{2}$, generally denoted by $\mathrm{X}^{-}$, see eqn (1). In this equation, $k_{1}$ is the third-order rate constant measured in the absence of $\mathrm{X}^{-}$(nitrosation by $\mathrm{NO}^{+}, \mathrm{HNO}_{2}+\mathrm{H}^{+} \rightleftarrows \mathrm{NO}^{+}\left(\mathrm{NOH}_{2} \mathrm{O}^{+}\right)$), whereas $k_{2}$ represents the nitrosation rate constant by $\mathrm{XNO}, \mathrm{HNO}_{2}+\mathrm{H}^{+}+\mathrm{X}^{-} \rightleftarrows \mathrm{XNO}$. The lower reactivity of the enol of AcAc than that of Ac or EMK, together with the high enol content of AcAc (the keto-enol equilibrium constant, $K_{\mathrm{E}}$, being of the order of 0.20 or 0.40$), \frac{8.9}{2}$ explains the different behaviour.

$$
\text { Rate }=\left(k_{1}+k_{2}\left[\mathrm{X}^{-}\right]\right)\left[\mathrm{H}^{+}\right][\mathrm{AcAc}]\left[\mathrm{HNO}_{2}\right]
$$

The nitrosation of AcAc was also studied in acetonitrile using tert-butylnitrite (tBN) as the nitrosating agent under experimental conditions of $[\mathrm{AcAc}] \gg[\mathrm{tBN}]$, with $[\mathrm{tBN}] \sim 1 \mathrm{mM}$, by noting the decreasing absorbance at $c a .380 \mathrm{~nm}$, due to nitrous acid or tBN consumption, or by noting the increasing absorption at $220 \mathrm{~nm}$, due to oxime formation. $\frac{10}{}$

Some years later, our group applied the use of aqueous micellar solutions to study the keto-enol equilibrium of 1,3-dicarbonyl compounds, such as AcAc. ${ }^{9.11}$ The value of the measured $K_{\mathrm{E}}=0.40$ was used in the analysis of the kinetic results obtained in the nitrosation of AcAc under experimental conditions of $\left[\mathrm{HNO}_{2}\right] \gg[\mathrm{AcAc}]$ (with $[\mathrm{AcAc}]=0.17 \mathrm{mM}$ and $[\mathrm{nit}]=3.1 \mathrm{mM}$ (nit means sodium nitrite)), uncontrolled ionic strength and following the nitrosation reaction by noting the decreasing absorbance at $274 \mathrm{~nm}$ due to the AcAc enol.

Taking into account the slight difference in ionic strength conditions used in the work of Williams' group ${ }^{\underline{5}}$ and our group, $\underline{9}$ along with the different values used for $K_{\mathrm{E}}$, the concordance between both sets of results is good, see Table 1 . 
Table 1 Experimental conditions and values of $k_{1}$ determined in the present work and compared with other published values

\section{This work $\quad \underline{\text { Ref. 9 }} \quad \underline{\text { Ref. } 5} \quad \underline{\text { Ref. 15 }}$}

\begin{tabular}{|c|c|c|c|c|c|}
\hline$\lambda / \mathrm{nm}$ & 230 & 274 & 385 & 275 !!! & \\
\hline$I / \mathrm{M}$ & 0.20 & Variable & 0.50 & 1.0 & \\
\hline$[\mathrm{AcAc}] / \mathrm{M}$ & $1 \times 10^{-3}$ & $0.17 \times 10^{-3}$ & 0.0487 & Variable & $5.3 \times 10^{-4}$ \\
\hline$[$ nit]/M & $5 \times 10^{-5}$ & $3.0 \times 10^{-3}$ & $2.1 \times 10^{-3}$ & $(4-5) \times 10^{-5}$ & \\
\hline$\left[\mathrm{H}^{+}\right] / \mathrm{M}$ & 0.20 & 0.20 & 0.138 & 0.13 & Variable \\
\hline$k_{1} / \mathrm{mol}^{-2} \mathrm{dm}^{6} \mathrm{~s}^{-1}$ & 5.4 & 4.2 & 5.9 & 8.45 & 10.4 \\
\hline
\end{tabular}

We continue to extend the nitrosation kinetic studies to other 1,3-dicarbonyl compounds. Hence, the nitrosation of 2-acetylcyclopentanone (ACPE) performed in an aqueous strong acid medium was, as expected, first-order with respect to both [ACPE] and [nit], but, in sharp contrast to other enolnitrosation reactions, the dependence of $\left[\mathrm{H}^{+}\right]$or $\left[\mathrm{X}^{-}\right]$is not a simple first-order catalysis, instead a fractional order which decreases from 1 to 0 on increasing $\left[\mathrm{X}^{-}\right]$(or $\left[\mathrm{H}^{+}\right]$) was observed. These kinetic observations were interpreted on the basis of an "unexpected" reaction mechanism in enol nitrosation, in which the enol is the species that undergoes nitrosation to give a chelate-nitrosyl complex (I) in steady-state, which is generated in the reversible step from the attack of the nitrosating agent, XNO, and subsequently rearranges to give the stable C-nitroso compound in the rate limiting step, $\underline{\text { Scheme }}$ $\underline{3}^{12}$

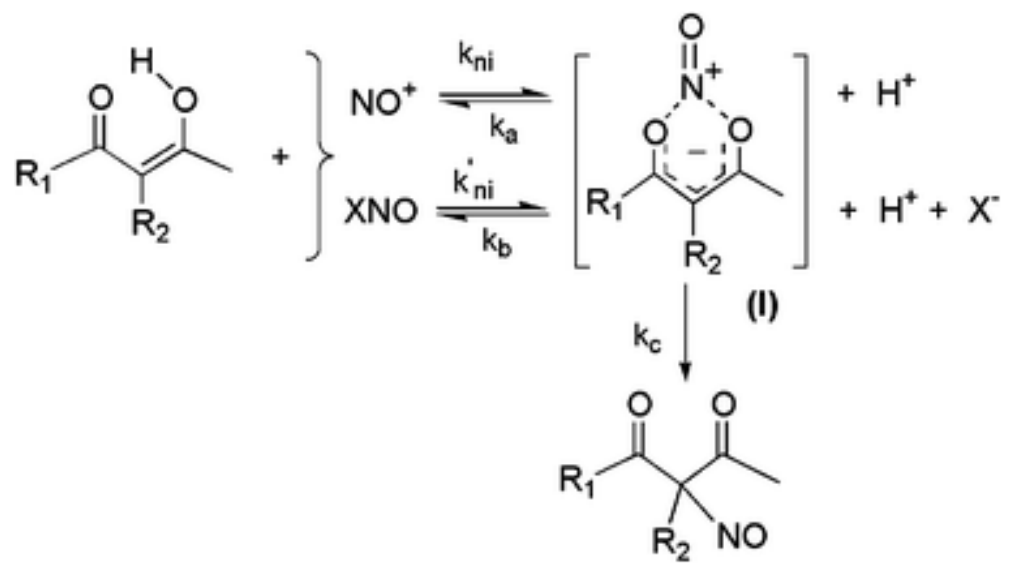

Scheme 3 . 
Quite a similar reaction scheme has been proposed in the nitrosation of 2-acetylcyclohexanone, ${ }^{13}$ 3-chloro-2,4-pentanedione or 3-ethyl-2,4-pentanedione. ${ }^{14}$

Recently, García-Rio et al. ${ }^{15,16}$ revised the nitrosation of AcAc in an aqueous medium. The authors proposed two reaction paths that involve, first, nitrosation through the $\mathrm{C}$-atom adjacent to the carbonyl - a step subject to nucleophilic catalysis - and, second, nitrosation through the O-atom of the enol - a step subject to acid-base catalysis. The experimental conditions used in this work were $\left[\mathrm{NaNO}_{2}\right](=$ $[$ nit $])=(4-5) \times 10^{-5} \mathrm{M} ;[\mathrm{AcAc}]=(0.5-5) \times 10^{-3} \mathrm{M}$, and different acidity conditions. According to the authors, the reaction rates were measured by monitoring the formation of the oxime product at 275 $\mathrm{nm} !$

The aim of this work is to demonstrate that, firstly, it is not possible to carry out the study of the nitrosation of AcAc by UV-vis spectroscopy at $275 \mathrm{~nm}$ under the experimental conditions of ref. 15 and, secondly, the reaction mechanism valid for the nitrosation of AcAc is that previously published in ref. 5 and 9 , where no acid-base catalysis was observed.

\section{Results}

Under the same experimental conditions used in the work of García-Rio et al., $\frac{15}{}$ we recorded the reaction spectra for the nitrosation of AcAc; $[$ nit $]=5 \times 10^{-5} \mathrm{M} ;[\mathrm{AcAc}]=1 \times 10^{-3} \mathrm{M}$, and $\left[\mathrm{H}^{+}\right]=0.20$ $\mathrm{M}\left(\mathrm{HClO}_{4}\right)$. As can be seen in Fig. 1 the band centered at $273 \mathrm{~nm}$, due to the enol of AcAc, does not change significantly with time, because AcAc is in great excess over nitrite, and, on the other hand, the absorption band due to $\mathrm{HNO}_{2}$ (observed between 350-400 nm) cannot be detected due to the low nitrite concentration. However, in aqueous perchloric acid, an absorption band appears at approximately $230 \mathrm{~nm}$, which has been used by Williams et al. ${ }^{10}$ in the study of the nitrosation of AcAc by tBN in acetonitrile. Therefore, under these experimental conditions, we measured the rate constant of the reaction by noting the increasing absorption at $230 \mathrm{~nm}$. Fig. $1 \mathrm{~b}$ shows the corresponding fit to the first-order integrated rate equation.

For comparison purposes, we list in Table 1 the third-order rate constant, $k_{1}$, corresponding to rate $=k_{1}\left[\mathrm{H}^{+}\right][$nit $][\mathrm{AcAc}]$, determined in the present study in aqueous perchloric acid, along with the published values and the corresponding experimental conditions. The $k_{1}$ values, determined either by Williams or by us, are in good agreement, but are nearly half the values reported in ref. 15 (see Table 1). We wonder if the substrate studied in the work of García-Rio et al. is really AcAc. Because the reaction of AcAc cannot be monitored by UV-vis at $275 \mathrm{~nm}$ under the experimental conditions of the work and the $k_{1}$ values differ very significantly either from those published or from that carefully measured in the present study. 

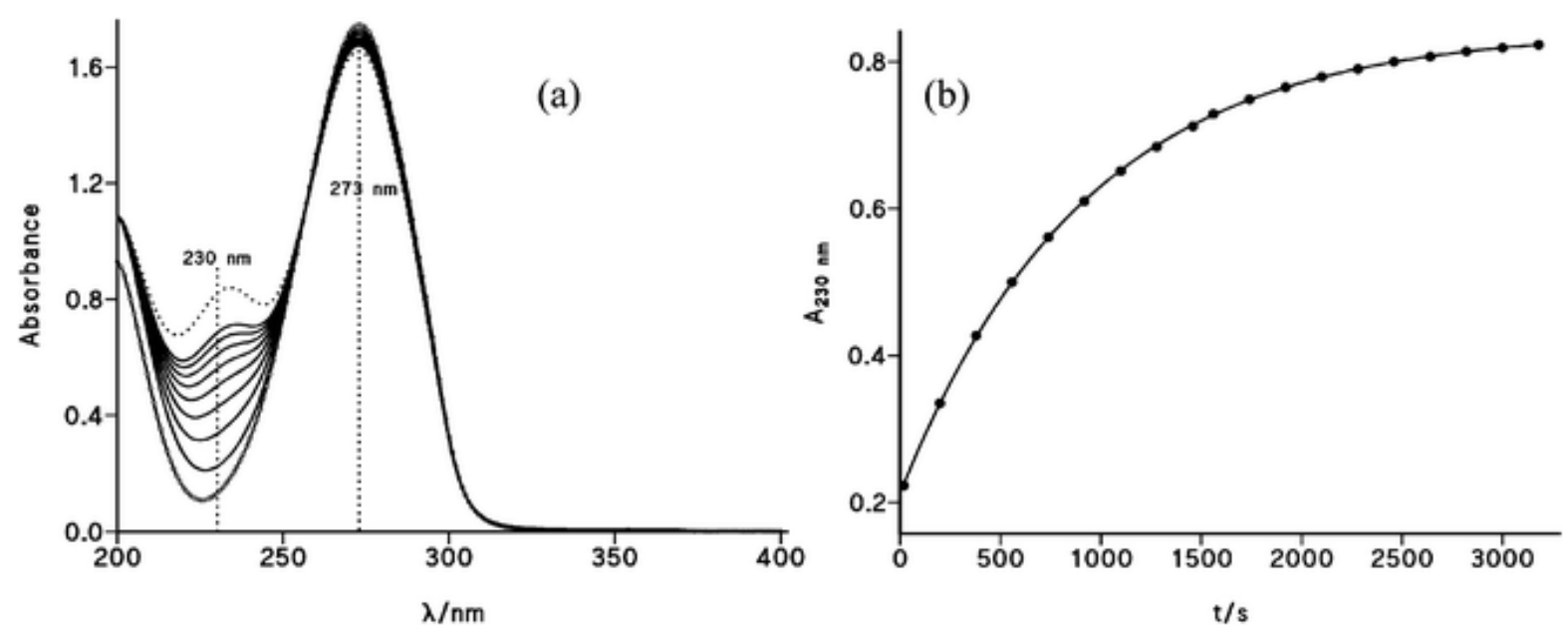

Fig. 1 (a) Reaction spectra (scans at 3 min intervals) for the nitrosation of AcAc at [nit] $=5 \times 10^{-5} \mathrm{M}$, [AcAc] = $1 \times 10^{-3} \mathrm{M}$, and $\left[\mathrm{H}^{+}\right]=0.20 \mathrm{M}\left(\mathrm{HClO}_{4}\right)$ showing the increasing absorption due to the oxime formation at 230 $\mathrm{nm}$; -o-o- spectrum of AcAc in the absence of nit; (...) spectrum at infinite time, and (b) absorbance values at $230 \mathrm{~nm}$ fit to the first-order integrated rate equation: $A_{\mathrm{t}}=A_{\infty}-\left(A_{\infty}-\mathrm{A}_{\mathrm{o}}\right) \exp \left(-k_{\mathrm{obs}} t\right)$ with $A_{\infty}=0.8433 \pm$ $0.0007 ; A_{\infty}-A_{\mathrm{o}}=0.6310 \pm 0.0009 ; k_{\mathrm{obs}}=(1.088 \pm 0.004) \times 10^{-3} \mathrm{~s}^{-1}$.

Fig. 2 shows the reaction spectrum under conditions of similar concentration values of AcAc and nit. There is a significant decrease of the absorption band centered at $273 \mathrm{~nm}$ due to enol consumption as the reaction proceeds, which draws two well-defined isosbestic points, and also decreasing absorbance between 350-400 $\mathrm{nm}$ due to nitrous acid. Following the reaction under these experimental conditions of second order with $[\mathrm{AcAc}] \sim[\mathrm{nit}]$ at $\left[\mathrm{H}^{+}\right]=0.20 \mathrm{M}$, the third-order rate constant is $k_{1}=$ $4.1 \mathrm{~mol}^{-2} \mathrm{dm}^{6} \mathrm{~s}^{-1}$, again in good agreement with the published data in ref. 5 and 9.

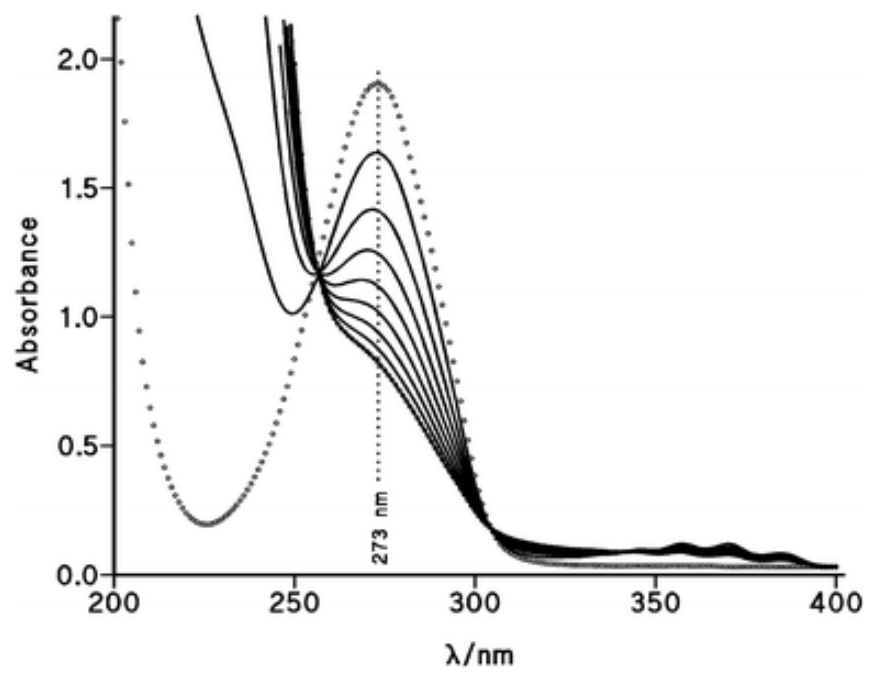

Fig. 2 Repeat scans each 3 min showing the decreasing absorption band due to enol in the reaction of [AcAc] = $1.0 \mathrm{mM}$ and $[$ nit $]=2 \mathrm{mM}$ at $\left[\mathrm{H}^{+}\right]=0.20 \mathrm{M}\left(\mathrm{HClO}_{4}\right)$; (o) absorption spectrum of AcAc $1.0 \mathrm{mM}$ in aqueous perchloric acid $0.20 \mathrm{M}$ in the absence of nitrite. 
Fig. 3 shows the reaction spectrum under the same experimental conditions of [AcAc] and [nit] of Fig. 2, but now in an aqueous buffer of trichloroacetic-trichloroacetate $\left(\mathrm{Cl}_{3} \mathrm{Ac}\right) 0.41 \mathrm{M}$. Decreasing absorption bands due to either AcAc-enol or $\mathrm{HNO}_{2}$ can also be seen. The same spectrum recorded at [nit $]=5 \times 10^{-5} \mathrm{M}$ does not show any variation, because of the strong absorption of the buffer below $260 \mathrm{~nm}$, approximately, and of the low absorption of nit in the 340-400 nm region. The third-order rate constant measured under these conditions by noting the decreasing absorbance at $273 \mathrm{~nm}$ was $k_{1}=$ $5.06 \mathrm{~mol}^{-2} \mathrm{dm}^{6} \mathrm{~s}^{-1}$. This value matches that measured in aqueous perchloric acid at the same $\left[\mathrm{H}^{+}\right]$of the buffer; this fact indicates that in $0.41 \mathrm{M}$ of total $\mathrm{Cl}_{3} \mathrm{Ac}$ buffer concentration the effect of the buffer is negligible.

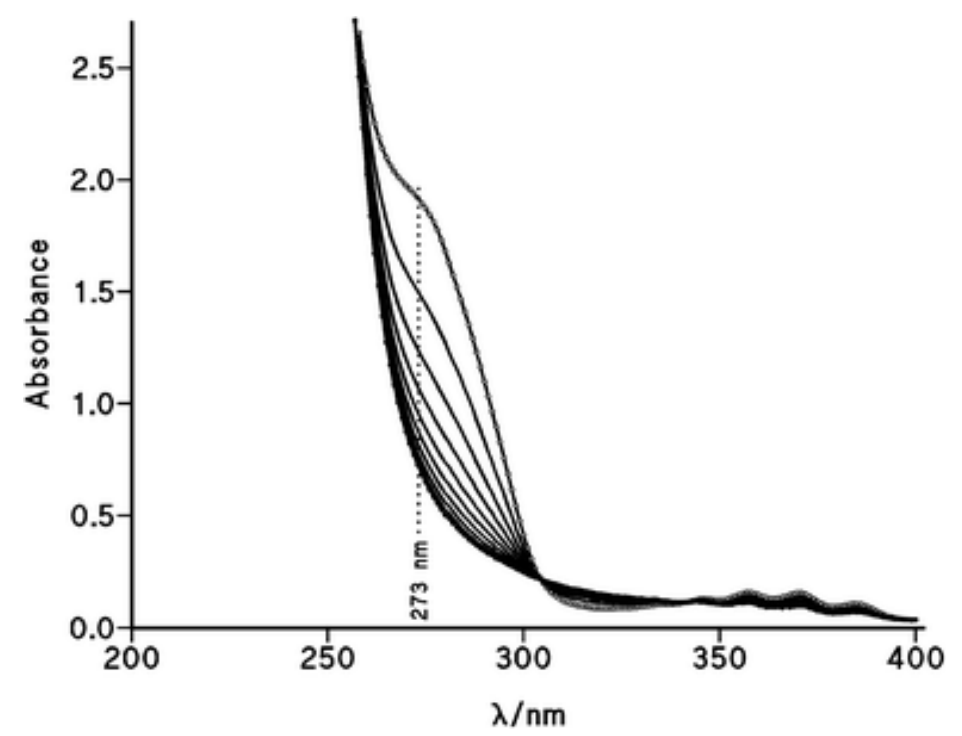

Fig. 3 Repeat scans each 3 min showing the decreasing absorption band due to enol in the reaction of [AcAc] = $1.0 \mathrm{mM}$ and $[\mathrm{nit}]=2 \mathrm{mM}$ in a buffer of trichloroacetic-trichloroacetate $\left[\mathrm{Cl}_{3} \mathrm{Ac}\right]=0.41 \mathrm{M}$.

In order to further investigate the effect of the buffers trichloroacetic, dichloroacetic $\left(\mathrm{Cl}_{2} \mathrm{Ac}\right)$ and monochloroacetic $(\mathrm{ClAc})$ acids, the nitrosation of AcAc was firstly studied in aqueous perchloric acid at $I=0.30 \mathrm{M}\left(\mathrm{NaClO}_{4}\right)$. Fig. 4 shows the variation of $k_{\mathrm{o}}\left(=k_{\mathrm{obs}} /[\mathrm{nit}]\right)$ as a function of $\left[\mathrm{H}^{+}\right]$under conditions of constant ionic strength, $0.30 \mathrm{M}\left(\mathrm{NaClO}_{4}\right)$, and variable ionic strength. The effect of ionic strength is a slight increase of $k_{\mathrm{o}}$, nearly a $20 \%$ increase; however, at $\left[\mathrm{H}^{+}\right]<0.20 \mathrm{M}$, approximately, the $k_{\mathrm{o}}$-values correlate almost linearly with $\left[\mathrm{H}^{+}\right]$(dotted line), but if one takes the whole $\left[\mathrm{H}^{+}\right]$interval, a smooth curve can be drawn. The same figure also shows the $k_{\mathrm{o}}$ values measured in buffers of $\mathrm{Cl}_{3} \mathrm{Ac}$ (open circles), $\mathrm{Cl}_{2} \mathrm{Ac}$ (open triangles), and $\mathrm{ClAc}$ (inverse open triangles close to the $0-0$ interception axis). The influence of $\mathrm{Cl}_{3} \mathrm{Ac}$ has been studied at $I=0.55 \mathrm{M}$; values of $k_{\mathrm{o}}$ determined at $\left[\mathrm{Cl}_{3} \mathrm{Ac}\right]=0.50$ $\mathrm{M}$ and variable $\left[\mathrm{H}^{+}\right]$agree perfectly with those obtained in aqueous perchloric acid solutions at the same acidity; at fixed $\left[\mathrm{H}^{+}\right]$a small increase of 1.35 -fold is observed when total $\left[\mathrm{Cl}_{3} \mathrm{Ac}\right]$ increases from 0.3 to $0.52 \mathrm{M}$. 


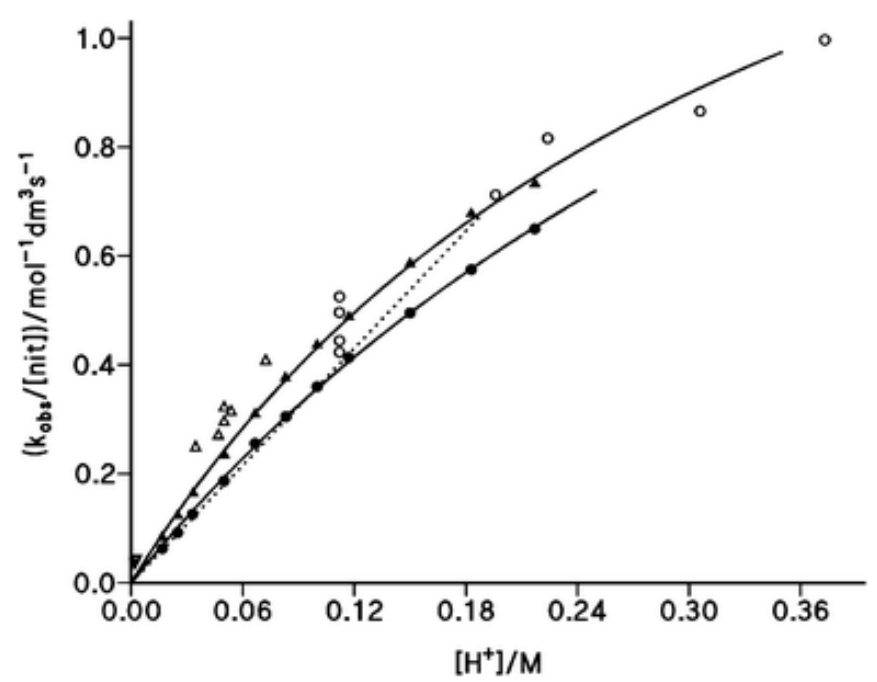

Fig. 4 Variation of $k_{\mathrm{o}}\left(=k_{\mathrm{obs}} /[\mathrm{nit}]\right)$ for the nitrosation of $\mathrm{AcAc}$ in an aqueous acid medium of $(\bullet) \mathrm{HClO}_{4}$ at $[\mathrm{AcAc}]=0.27 \mathrm{mM} ;[$ nit $]=8.3 \mathrm{mM}$, and uncontrolled ionic strength; $(\mathbf{\Delta}) \mathrm{HClO}_{4}$ at $[\mathrm{AcAc}]=0.21 \mathrm{mM} ;[\mathrm{nit}]=$ $6.7 \mathrm{mM}$, and ionic strength $0.30 \mathrm{M}\left(\mathrm{NaClO}_{4}\right)$; (o) $\mathrm{Cl}_{3} \mathrm{Ac} 0.53 \mathrm{M}$ at variable trichloroacetic/trichloroacetate ratios and $[\mathrm{AcAc}]=0.21 \mathrm{mM},[\mathrm{nit}]=6.7 \mathrm{mM}$; ionic strength $0.50 \mathrm{M}$, and $(\Delta) \mathrm{Cl}_{2} \mathrm{Ac}$ and $(\nabla) \mathrm{ClAc}-$ see all points close to the $0-0$ interception axis - at ionic strength $0.35 \mathrm{M}$ and equal AcAc and nit concentrations as for $\mathrm{Cl}_{3}$ Ac. Solid lines fit to eqn (2).

The results in Fig. 4 can be easily explained on the basis of the reaction in $\underline{\text { Scheme } 3}$. The observed rate constant derived from this scheme is that of eqn (2). To arrive at this equation, it is necessary to take into account that: $[\mathrm{AcAc}]=[\mathrm{KH}]+[\mathrm{EH}](\mathrm{KH}=$ keto form, $\mathrm{EH}=$ enol form $)$; $[$ nit $]=\left[\mathrm{HNO}_{2}\right]$ (the $\mathrm{p} K_{\mathrm{a}}$ of $\mathrm{HNO}_{2}$ is 3.13), $\frac{17}{}$ and the equilibrium of nitrosating agent formation, $\mathrm{HNO}_{2}+$ $\mathrm{H}^{+} \rightleftarrows \mathrm{NO}^{+}\left(\mathrm{NO}^{+} \mathrm{OH}_{2}\right), K_{\mathrm{NO}}\left(=3.5 \times 10^{-7} \mathrm{~mol}^{-1} \mathrm{dm}^{3}\right) . \underline{18}$

$$
k_{\text {obs }}=\frac{k_{\mathrm{ni}} K_{\mathrm{NO}}\left(K_{\mathrm{E}} / 1+K_{\mathrm{E}}\right)[\mathrm{nit}]\left[\mathrm{H}^{+}\right]}{1+\left(k_{\mathrm{a}} / k_{\mathrm{c}}\right)\left[\mathrm{H}^{+}\right]}
$$

The non-linear regression analysis of the experimental data according to eqn (2) affords the following values of $k_{\mathrm{a}} / k_{\mathrm{c}}=2.8 \pm 0.2 \mathrm{M}^{-1}$ and $k_{\mathrm{ni}} K_{\mathrm{NO}} K_{\mathrm{E}} /\left(1+K_{\mathrm{E}}\right)=5.6 \pm 0.1 \mathrm{M}^{-1} \mathrm{~s}^{-1}$ at $I=0.30 \mathrm{M}$, and $1.9 \pm 0.1 \mathrm{M}^{-1}$ and $4.23 \pm 0.07 \mathrm{M}^{-1} \mathrm{~s}^{-1}$ at uncontrolled ionic strength, see the solid lines in Fig. 4. These values give $k_{\mathrm{ni}}$ results $\left(k_{\mathrm{ni}}=5.6 \times 10^{7} \mathrm{M}^{-1} \mathrm{~s}^{-1}\right.$ and $4.2 \times 10^{7} \mathrm{M}^{-1} \mathrm{~s}^{-1}$, respectively) in good agreement with those already published $d^{4.9}\left(k_{\mathrm{ni}}=6.0 \times 10^{7} \mathrm{M}^{-1} \mathrm{~s}^{-1}\right.$ and $4.4 \times 10^{7} \mathrm{M}^{-1} \mathrm{~s}^{-1}$ by using $\left.K_{\mathrm{E}}=0.4\right)$.

From the data reported in the caption of Fig. 2 of ref. 15 we simulate the expected results of $k_{\mathrm{o}}\left(=k_{\mathrm{obs}} /[\mathrm{AcAc}]\right)$ in order to compare them with those measured in the present work. These results are shown in Fig. 5(a), along with the values obtained in the present study. As can be seen the difference is clearly evident. 

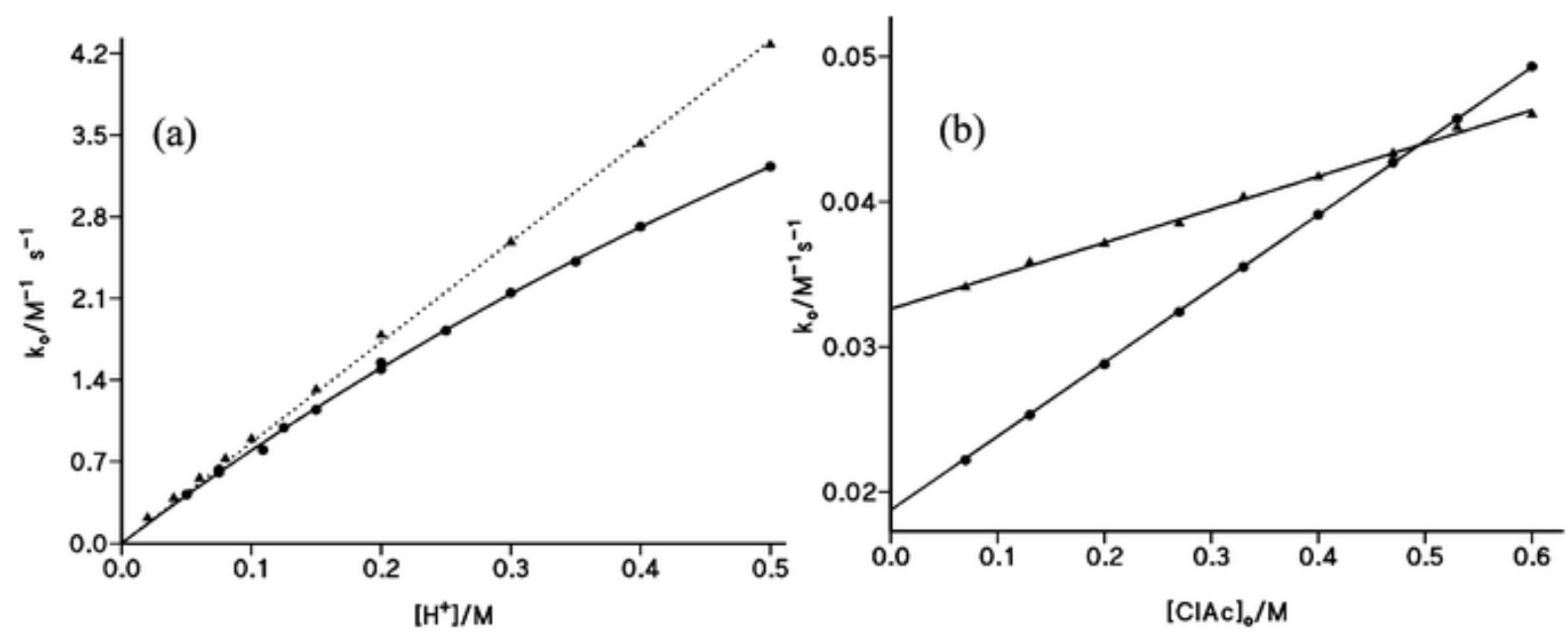

Fig. 5 (a) Plot of $k_{\mathrm{o}}\left(=k_{\mathrm{obs}} /[\mathrm{AcAc}](\bullet)\right.$ determined in this work noting the increasing absorbance at $230 \mathrm{~nm}$ at $[\mathrm{AcAc}]=1 \mathrm{mM}$ and $[\mathrm{nit}]=6 \times 10^{-5} \mathrm{M}$ in aqueous perchloric acid of ionic strength $0.60 \mathrm{M}$, and $(\boldsymbol{\Delta})$ values of $k_{\mathrm{o}}$ calculated from data in ref. 15; (b) plot of $k_{\mathrm{o}}$ against the total buffer concentration of monochloroacetic, $\mathrm{ClAc}$, calculated from data in ref. $15(\bullet)$ and obtained in the present study $(\boldsymbol{\Delta})$.

In the same sense, Fig. 5(b) shows the result of the influence of the monochloroacetic acidmonochloroacetate buffer at $\mathrm{pH} 2.69$. As can be seen, $k_{\mathrm{o}}$ correlates linearly with [buffer] at constant $\mathrm{pH}$, but the effect of [buffer] observed in this study is much lower than that published in ref. 15, even though both studies afford rate constants of the same order of magnitude.

\section{Discussion}

The observed experimental facts in the present revision study can be explained on the basis of the already published reaction mechanism by noting some details. The nitrosation of AcAc occurs by the NO-transfer from the nitrosating agent XNO to the O-atom of the carbonyl group to form, in the first step, the nitrosyl complex intermediate in steady state, which rearranges to the final C-nitroso compound or to the oxime - when possible - in the rate limiting step, $\underline{\text { Scheme } 3}$. In general, high $\left[\mathrm{H}^{+}\right]$ and/or high $[\mathrm{X}]$ are required to achieve the steady-state approximation, but the exact conditions depend on the nature of the diketone. The small effect of the acetic acid-acetate buffer and its chloroderivatives is due to the formation of nitrosyl acetate, which increases the reaction rate as do CINO, BrNO or SCNNO.

Several key points have not been considered in the work of García-Rio et al. The first is concerned with the formation of nitrosyl acetate (AcONO) and its chloroderivatives. Acetate is a stronger base than e.g. trichloroacetate; therefore, the base catalytic effect should be better observed in acetic buffer than in trichloroacetic buffer. By contrast, in the sense of forming nitrosyl compounds, trichloroacetate resembles more, for instance, $\mathrm{Cl}^{-}, \mathrm{Br}^{-}$or $\mathrm{SCN}^{-}$, than acetate does. In this regard, Kozlov et al. ${ }^{19}$ found 
a $30 \%$ yield of $\mathrm{AcONO}$ against $44 \%$ of $\mathrm{ClAcONO}$ or $40 \%$ of $\mathrm{Cl}_{3} \mathrm{CCONO}$ in the reaction of the corresponding acid with $\mathrm{NaNO}_{2}$.

In the present work, we found that, at $\mathrm{pH}$ values close to the $\mathrm{p} K_{\mathrm{a}}$ of the corresponding buffer, an increase of e.g. 1.7-fold the total buffer concentration results in an increase of the observed rate constant, $k_{\mathrm{obs}}$, of $1.05,1.20$, and 1.35, respectively, for chloroacetate, dichloroacetate, and trichloroacetate buffers, see Table S1.I That is, the catalytic effect is opposite to the strength of the base component of the buffer, which means that the catalytic effect cannot be attributed to the base catalysis. In this respect, it is worth recalling that the buffering capacity of $\mathrm{Cl}_{3} \mathrm{Ac}, \mathrm{Cl}_{2} \mathrm{Ac}$ or $\mathrm{ClAc}$ is small and one has to be very careful when working with these buffers; otherwise, the effect of $\mathrm{pH}$ could be wrongly interpreted as a buffer concentration effect.

As the second point, assuming that the experiments of ref. 15 were performed under $\left[\mathrm{HNO}_{2}\right] \ll$ [AcAc], and thus $\left[\mathrm{HNO}_{2}\right] \ll[$ buffer], according to the published results on azide nitrosation in acetate buffer, $\underline{20}$ the first postulated step of the reaction $\mathrm{AcO}^{-}+\mathrm{HNO}_{2}+\mathrm{H}^{+} \rightleftarrows$ AcONO is strongly shifted to nitrosyl acetate formation, and the second step of AcONO $+\mathrm{NO}_{2}^{-} \rightleftarrows \mathrm{N}_{2} \mathrm{O}_{3}+\mathrm{AcO}^{-}$is negligible, especially in $\mathrm{Cl}_{2} \mathrm{Ac}$ or $\mathrm{Cl}_{3} \mathrm{Ac}$. This is the reason why in the nitrosation performed in acetic acid buffer under conditions of $\left[\mathrm{HNO}_{2}\right] \gg$ [substrate], only nitrosation by $\mathrm{N}_{2} \mathrm{O}_{3}$ is observed.

There are several bibliographic references on the characterization of nitrosyl acetate (or acetyl nitrite) and its chloroderivatives. Kennedy et $a l^{.}{ }^{21}$ have developed a model that predicts, first, that AcONO is more reactive than $\mathrm{N}_{2} \mathrm{O}_{3}$ and, second, the equilibrium constant of AcONO formation, i.e. $\mathrm{AcO}^{-}+\mathrm{HNO}_{2}+\mathrm{H}^{+} \rightleftarrows \mathrm{AcONO}$, was determined as $4.4 \times 10^{-6} \mathrm{M}^{-2}$, which means that at the same $\mathrm{pH}$ value, $[\mathrm{AcONO}] \approx 20\left[\mathrm{NO}^{+}\right]$. In a very recent study $\underline{22}$ the formation enthalpy at $298 \mathrm{~K}$ of acetyl nitrite has been determined as $\Delta H_{\mathrm{f}}^{\circ}=-58.2 \mathrm{kcal} \mathrm{mol}^{-1}$, using density functional B3LYP and CRS-QB3 computations; this study also shows an intramolecular transfer reaction (isomerization) with a low energy barrier of $3.6 \mathrm{kcal} \mathrm{mol}^{-1}$ in the acetyl nitrite, where the $\mathrm{NO}$ moves to the $\mathrm{C}=\mathrm{O}$ oxygen in the motion of a stretching frequency. In the same sense, a communication of $1982^{\underline{23}}$ describes the preparation of acetyl nitrite in the reaction of silver acetate and nitrosyl chloride. On the other hand, the preparation of acyl nitrites from an aqueous mixture of the corresponding carboxylic acid and sodium nitrite yielded $44 \%$ of $\mathrm{ClCH}_{2} \mathrm{COONO}$ and $40 \%$ of $\mathrm{Cl}_{3} \mathrm{CCOONO}$ and the spectral characterization of the system reveals that at high $\mathrm{HNO}_{2}$ concentration, the equilibrium AcONO + $\mathrm{HNO}_{2} \rightleftarrows \mathrm{N}_{2} \mathrm{O}_{3}+\mathrm{AcOH}$ is established. $\underline{19}$

From the point of view of kinetic studies, the work of Casado et al. ${ }^{24}$ shows that the nitrosation of the amino group in amino acids proceeds via the initial formation of nitrosyl carboxylate followed by an intramolecular NO migration from oxygen to nitrogen. This research group also found that AcONO is the only nitrosating species in the nitrosation of $N$-methyl-phenylamine, even though its concentration is very low; by contrast, in the nitrosation of morpholine (a less basic amine) the 
nitrosation occurs solely by $\mathrm{N}_{2} \mathrm{O}_{3}$, but the catalysis observed by the acetic acid-acetate buffer under conditions where the rate controlling step is not the nitrosation is due to the increase in $\mathrm{N}_{2} \mathrm{O}_{3}, 25$ in accordance with the work of Kozlov et al. ${ }^{19}$ and Stedman. ${ }^{20}$

Further evidence on behalf of the reaction mechanism involving the nitrosyl complex formation, stated in $\underline{\text { Scheme 3 }}$, is the ability of 1,3-diketones to form a chelate complex with metal ions, such as $\mathrm{Fe}^{3+}, \mathrm{Cu}^{2+}, \mathrm{Tl}^{+}$, etc. $\left(\mathrm{NO}^{+}\right.$is also a cation). ${ }^{\frac{26,27}{2}}$ The formation of nitrosyl or metal ion complexes increases the acidity of the proton of the enol several thousand times. In fact, when metal ions react with 1,3-diketones, the final product is invariably the metal-enolate complex and the majority of metal ions only react with either the enolate ion or the enol tautomer.

\section{Conclusions}

The experimental conditions of acetylacetone nitrosation in water have been revised very carefully and it can be concluded that the reaction cannot be followed at $275 \mathrm{~nm}$ under conditions of [nit] « [AcAc]. The kinetic results obtained in the present study are in complete agreement with those previously published by Williams or by us, but disagree with the results of García-Rio: the effect of buffers derived from acetic acid cannot be attributed to base catalysis. Several literature references on the formation of nitrosyl acetate - and its chloroderivatives - in aqueous solutions of sodium nitrite, on the characterization of these species, and on their influence on nitrosation reactions must be considered. Therefore, the kinetic features of acetylacetone nitrosation are consistent with the reaction mechanism proposed in $\underline{\text { Scheme } 3}$, which can be simplified depending on the experimental conditions, and the small effect of buffers is due to the increase of nitrosating agent concentration because of the formation of nitrosyl salts derived from acetate or its chloroderivatives.

\section{Experimental}

Acetylacetone, Aldrich, of maximum purity, $+99 \%$, was stored in a refrigerator and used as received (purification by fractional low-pressure distillation before using it does not change the results). The remaining reagents (Merck) were used as supplied. All solutions were prepared with double distilled water obtained from permanganate solution.

Pure acetylacetone was dissolved in dioxane (spectrophotometric grade). From this stock solution, the working aqueous solution was daily prepared by diluting the appropriate volume $(0.2-0.4 \mathrm{ml})$ in a $25 \mathrm{ml}$ final volume of the required concentration. UV-VIS absorption spectra and kinetic measurements were recorded with a Kontron-Uvikon 942 double beam spectrophotometer, provided with a multiple cell carrier thermostatted at $25{ }^{\circ} \mathrm{C}$ by circulating water. The $\mathrm{pH}$ was measured with a Crison $2001 \mathrm{pH}$-meter equipped with a GK2401B combined glass electrode and calibrated using 
commercial buffers of $\mathrm{pH} 4.01$ and 7.02 (Crison). The reported [buffer] refers to the total buffer concentration.

Kinetic experiments were carried out under pseudo-first order conditions and, in some cases, under second order conditions. In every kinetic experiment, the sodium nitrite aqueous solution, previously thermostatted at the same temperature as the rest of the reaction mixture, was added $(0.10-0.20 \mathrm{ml})$ to start the reaction; this procedure guarantees that keto-enol equilibrium is achieved before the reaction starts. In each case the integrated method was followed, fitting the experimental absorbance-time data to either the first-order integrated rate equation or to the second order one; satisfactory correlation coefficients $(>0.999)$ were obtained in all cases.

\section{Acknowledgements}

Financial support from the Dirección General de Programas y Transferencia de Conocimiento (Ministerio de Ciencia e Innovación) of Spain (Project CTQ2008-04429/BQU) is gratefully acknowledged.

\section{References}

1. O. Touster, Organic Reactions, ed. R. Adams, Wiley, New York, 1953, ch. 6, vol. 7, p. 327

2. K. singer and P. M. Vamplew, J. Chem. Soc., 1957, 3050

3. M. M. Rogic, J. vitrone and M. D. Swerdloff, J. Am. Chem. Soc., Chem. Commun., 1977, 1156

4. J. R. Leis, M. E. Peña and D. L. H. Williams, J. Chem. Soc., Chem. Commun., 1987, 45

5. J. R. Leis, M. E. Peña, D. L. H. Williams and S. D. Mawson, J. Chem. Soc., Perkin Trans. 2, 1988, 157

6. P. Hervés-Beloso, P. Roy and D. L. H. Williams, J. Chem. Soc., Perkin Trans. 2, 1991, 17

7. A. Graham and D. L. H. Williams, J. Chem. Soc., Perkin Trans. 2, 1992, 747

8. (a) S. G. Mills and P. Beak, J. Org. Chem., 1985, 50, 1216; (b) A. S. N. Murthy, A. Balasubramanian and C. N. R. Rao, Can. J. Chem., 1962, 40, 2267 ; (c) S. J. Rhoads and C. Pryde, J. Org. Chem., 1965, 30, 3212

9. E. Iglesias, J. Chem. Soc., Perkin Trans. 2, 1997, 431

10. M. J. Crookes, P. Roy and D. L. H. Williams, J. Chem. Soc., Perkin Trans. 2, 1989, 1015.

11. (a) E. Iglesias, J. Phys. Chem., 1996, 100, 12592 ; (b) Langmuir, 2001, 17, 6871

12. E. Iglesias, New J. Chem., 2002, 26, 1352

13. E. Iglesias, J. Org. Chem., 2003, 68, 2689 
14. E. Iglesias, Int. J. Chem. Kinet., 2012, 44(10), 668-679 L. García-Rio, J. C. Mejuto, M. Parajó and M. Pérez-Lorenzo, J. Org. Chem., 2008, 73, 8198 .

15. L. García-Rio, J. C. Mejuto, M. Parajó and M. Pérez-Lorenzo, Eur. J. Org. Chem., 2009, 4525

16. J. Tummavouri and P. Lumme, Acta Chem. Scand., 1965, 19, 617

17. J. H. Ridd, Adv. Phys. Org. Chem., 1978, 16, 1 and references therein.

18. CAPLUS Database Abstract of: V. V. Kozlov and B. I. Bolov, Zh. Obshch. Khim., 1963, 33, 1951

19. G. Stedman, J. Chem. Soc., 1960, 1702

20. G. da Silva, E. M. Kennedy and B. Z. Dlugogorski, J. Chem. Res., 2002, 589

21. S. Snitsiriwat, R. Asatryan and J. W. Bozzelli, J. Phys. Chem. A, 2011, 115, 13921

22. A. B. Kyte, R. Jones-Perry and D. Whihaker, J. Chem. Soc., Chem. Commun., 1982, 74

23. (a) J. Casado, A. Castro, J. R. Leis, M. Mosquera and M. E. Peña, J. Chem. Soc., Perkin Trans. 2, 1985, 1859 ; (b) R. Gil, J. Casado and C. Izquierdo, Int. J. Chem. Kinet., 1994, 26, 1167

24. J. Casado, A. Castro, M. A. López-Quintela, M. Mosquera and M. F. Rodríguez-Prieto, Monatsh. Chem., 1983, 114, 647

25. M. J. Hynes, Rev. Inorg. Chem., 1990, 11, 21 and references therein.

26. M. J. Hynes, C. A. Blanco and M. T. Mooney, J. Chem. Soc., Perkin Trans. 2, 1991, 2055 